\author{
SUPPORTING INFORMATION
}

\title{
Uranium(VI) complexes of glutathione disulfide forming in aqueous solution
}

Jerome Kretzschmar,* Alexander Strobel,$\uparrow$ Toni Haubitz, $₫$ Björn Drobot, Robin Steudtner, Astrid Barkleit, Vinzenz Brendler, and Thorsten Stumpf

Helmholtz-Zentrum Dresden-Rossendorf, Institute of Resource Ecology, Bautzner Landstr. 400, 01328 Dresden, Germany

$\dagger$ (present address) Helmholtz-Zentrum Dresden-Rossendorf, Institute of Ion Beam Physics and Materials Research, Bautzner Landstr. 400, 01328

Dresden, Germany

$\$$ (present address) Institute of Chemistry, University Potsdam, KarlLiebknecht-Str. 24-25, Building 29, 14476 Potsdam OT Golm, Germany

* Corresponding author:

E-mail: j.kretzschmar@hzdr.de

The Supporting Information comprises 25 pages, including 20 figures, 3 tables, and 10 references. 

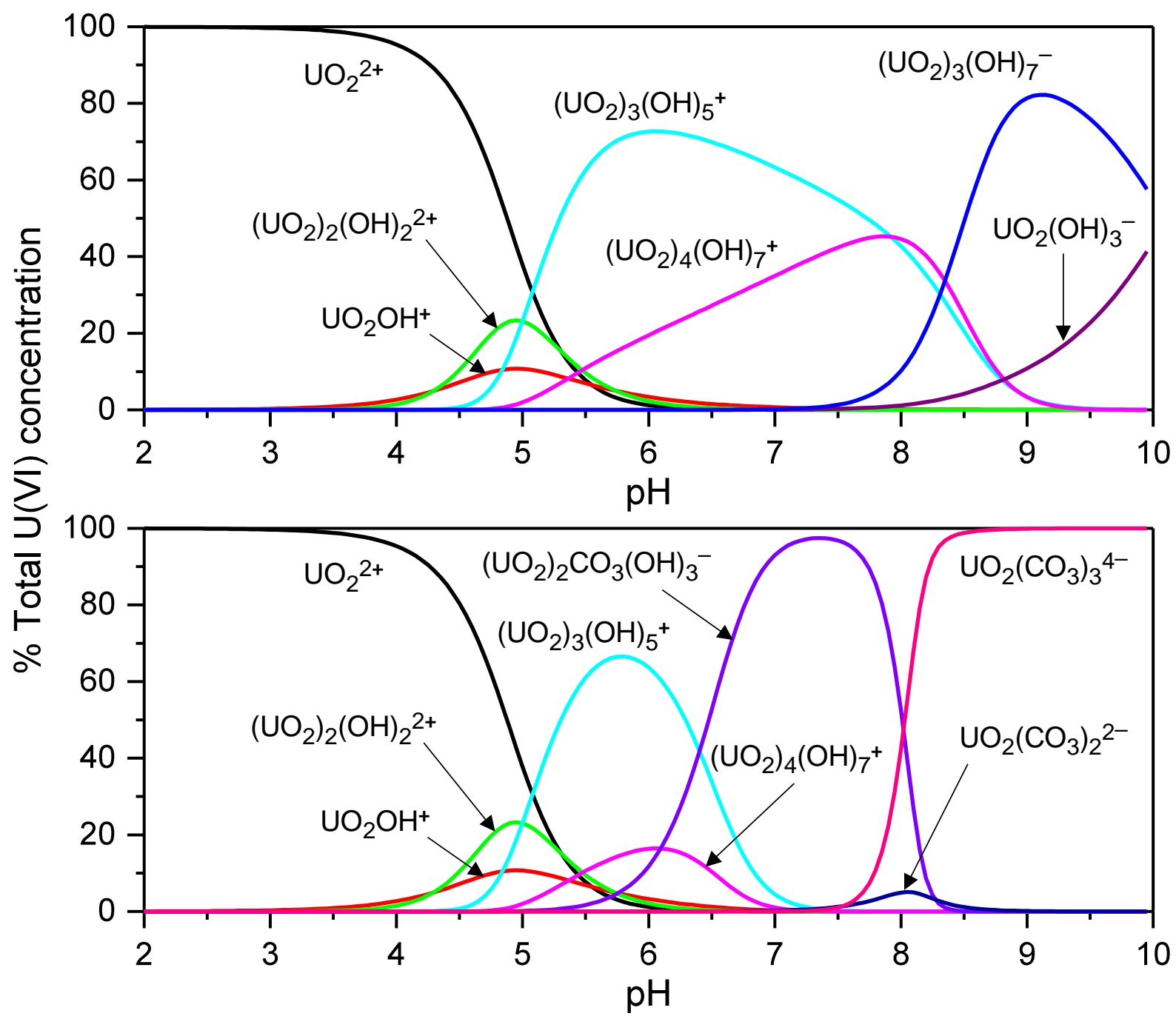

Figure S1. Aquatic speciation of $1 \times 10^{-4} \mathrm{M} \mathrm{U}(\mathrm{VI})$ in $0.1 \mathrm{M} \mathrm{NaClO}_{4}$ at $25^{\circ} \mathrm{C}$ under nitrogen (top) and ambient atmosphere (bottom). Speciation was calculated with the EQ3/6 package ${ }^{1}$ using the most updated thermodynamic data from NEA TDB. ${ }^{2}$ Note that only species of at least $3 \%$ total U(VI) concentration are displayed. 

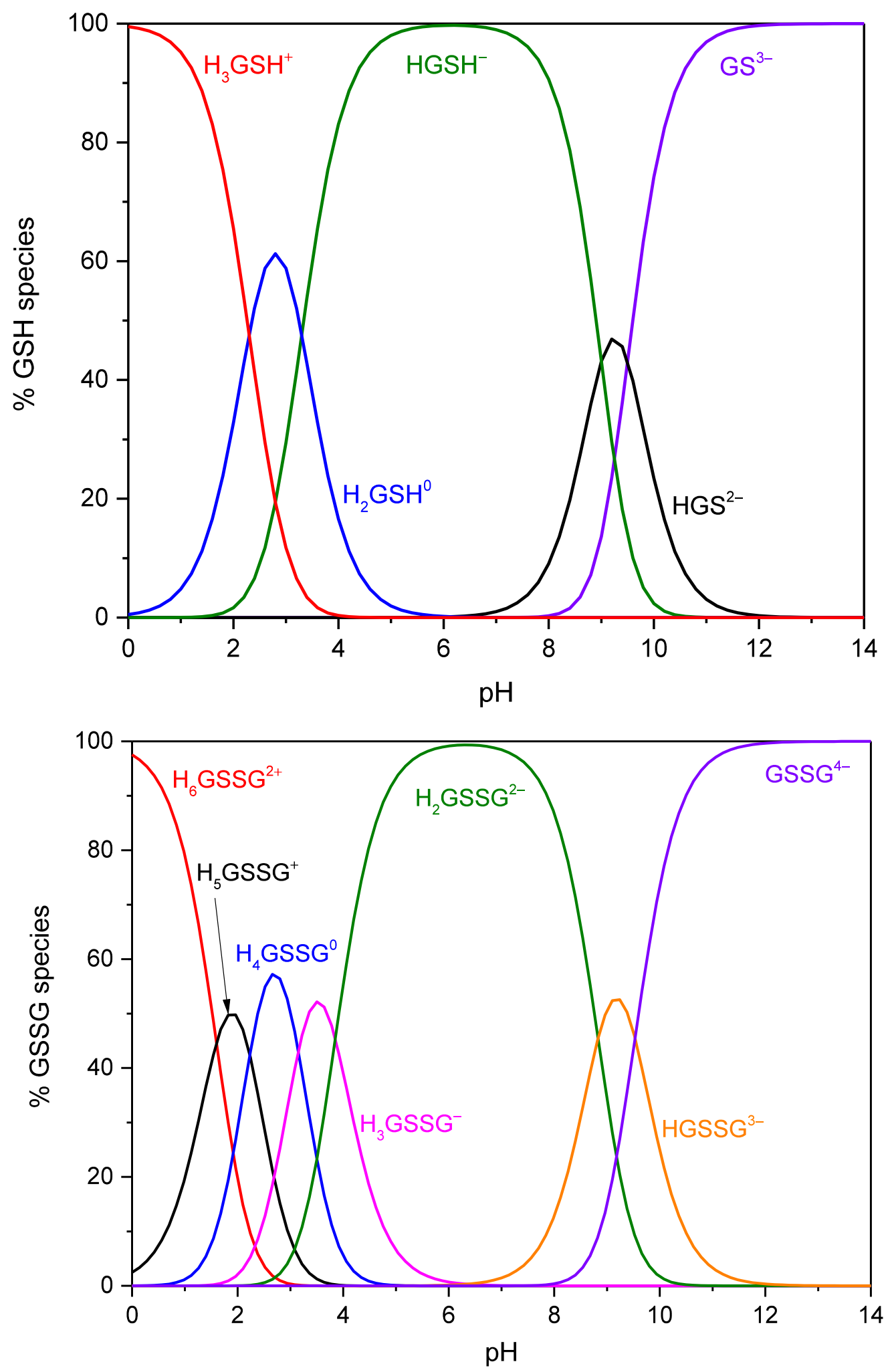

Figure S2. Speciation diagrams of GSH (top) and GSSG (bottom). Speciation was calculated with HySS2009 ${ }^{3}$ using thermodynamic data from ref. 4 (GSSG) and ref. 5 (GSH). 
Table S1. Complexation-induced shifts for pD 2 solutions of GSSG and U(VI) according to the spectra shown in Figure 2 (main text).

\begin{tabular}{ccccc}
\hline $\begin{array}{c}\text { [GSS] }:[\mathrm{U}(\mathrm{VI})] \\
(\mathrm{mM})\end{array}$ & Glu $\alpha$ & Glu $\beta$ & Glu $\gamma$ & Gly $\alpha$ \\
\cline { 2 - 5 } & 9 & 4 & 3 & 3 \\
$9.6: 0.5$ & 56 & 37 & 25 & 20 \\
$8.4: 4.7$ & 97 & 57 & 39 & 29 \\
$9.8: 8.7$ & 290 & 211 & 145 & 146 \\
$5.5: 89$ & & & & \\
\hline \hline
\end{tabular}




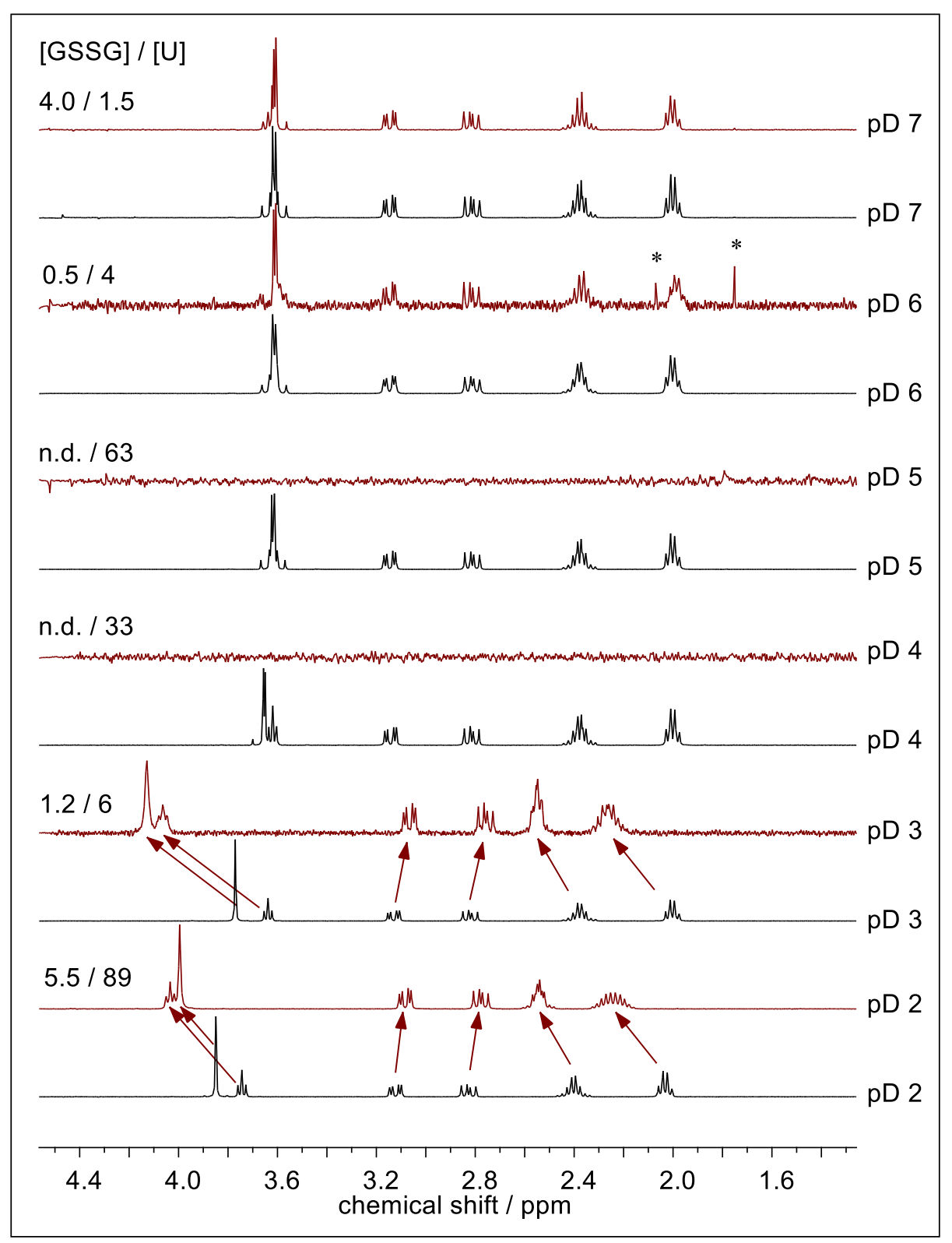

Figure S3. ${ }^{1} \mathrm{H}$ NMR pD-dependent spectra of GSSG blanks (black) and U(VI) containing solutions (red). Initial concentrations for GSSG (both blank and sample) were $10 \mathrm{mM}$, and for U(VI) $100 \mathrm{mM}$, with the re-determined concentrations stated with the spectra; $(*)$ denotes an impurity; n.d.: not detectable.

The NMR spectra of the pD 4 and pD 5 samples show no GSSG signals at all, indicating that the precipitate formed during sample preparation contains GSSG bound to U(VI). The pD 6 sample is still low in GSSG concentration (note the noisy spectrum), but shows only marginal spectra alterations implying only small amounts of dissolved (ternary) hydroxo GSSG-U(VI) complex. Considering the amount of $\mathrm{U}(\mathrm{VI})$ remaining in solution, viz. 33 and $63 \mathrm{mM}$ for $\mathrm{pD} 4$ and 5 , respectively, by implication remarkable amounts of $\mathrm{U}(\mathrm{VI})$ were removed from solution when the predominating GSSG species bear a net charge of -1 or -2 , respectively. 


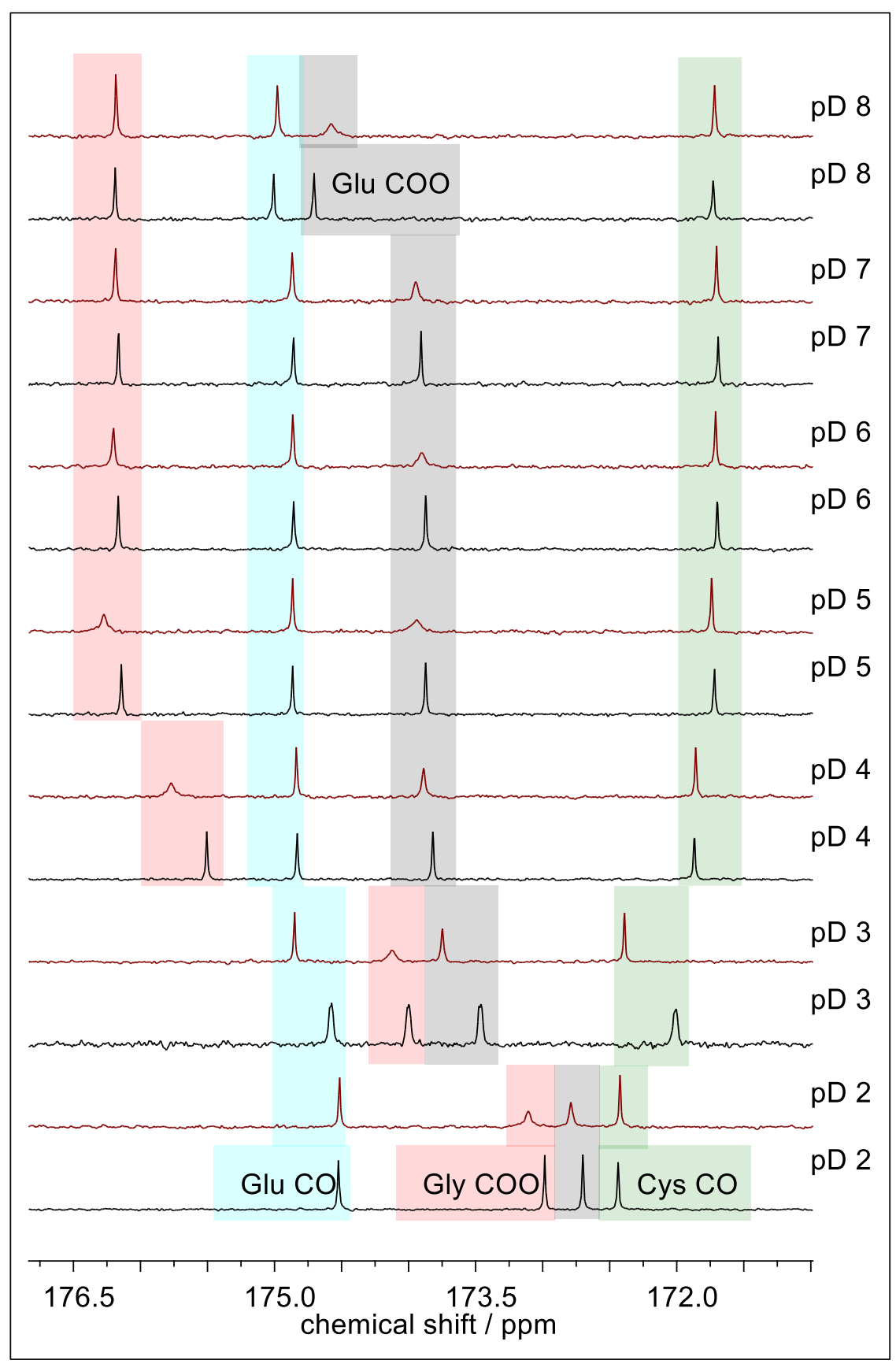

Figure S4. ${ }^{13} \mathrm{C}\left\{{ }^{1} \mathrm{H}\right\}$ NMR carboxyl/carbonyl region of pD-dependent spectra of GSSG blanks (black) and U(VI) containing solutions (red). Initial $[\mathrm{GSSG}]=150 \mathrm{mM}$ (for both blank and sample), and $[\mathrm{U}(\mathrm{VI})]=7.5 \mathrm{mM}(\mathrm{L} / \mathrm{M}=20)$, respectively. For clarity, signals of the individual sites are color-coded. 


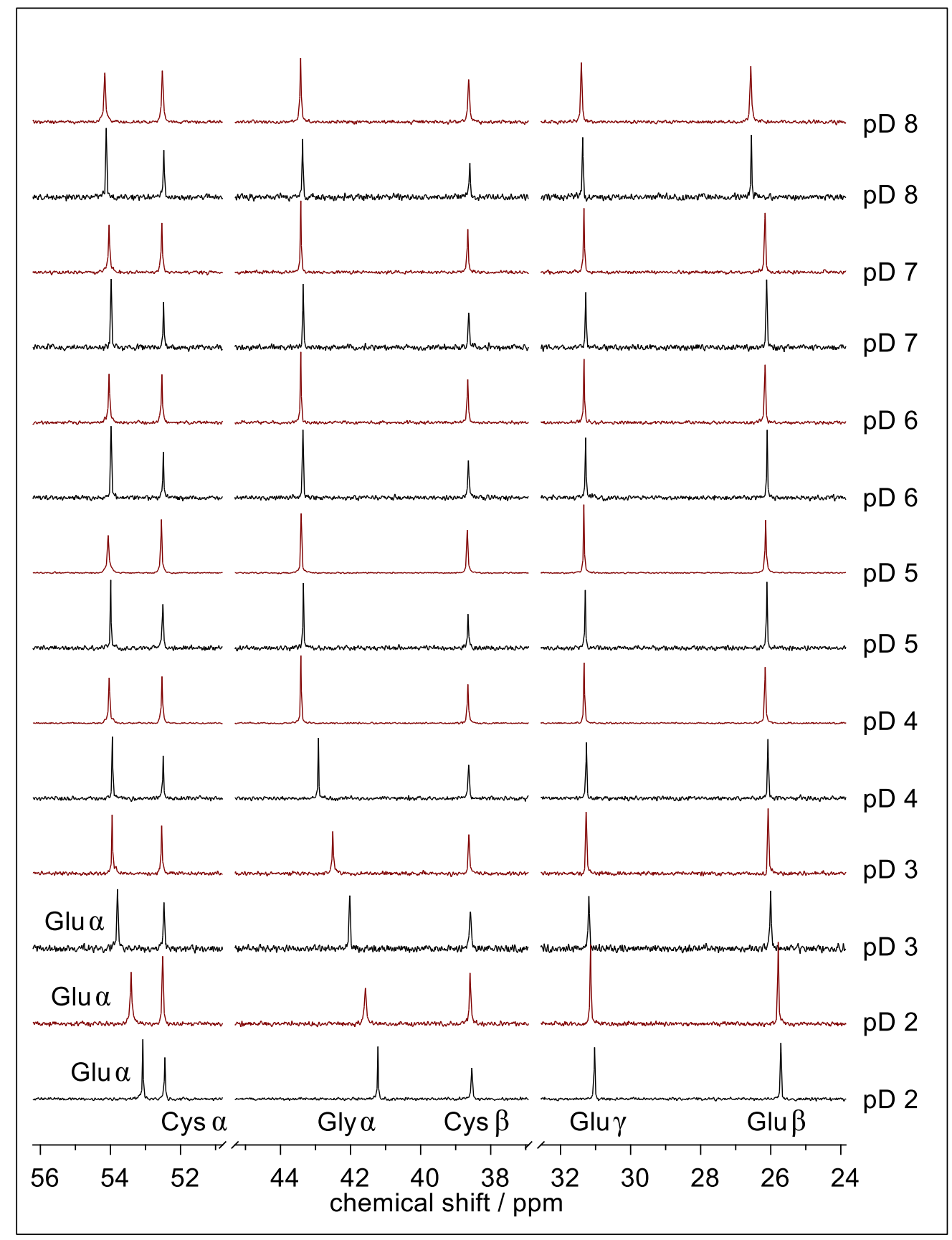

Figure S5. ${ }^{13} \mathrm{C}\left\{{ }^{1} \mathrm{H}\right\}$ NMR aliphatic region of pD-dependent spectra of GSSG blanks (black) and U(VI) containing solutions (red). Initial [GSSG] $=150 \mathrm{mM}$ (for both blank and sample) and $[\mathrm{U}(\mathrm{VI})]=75 \mathrm{mM}(\mathrm{L} / \mathrm{M}=2)$, respectively. 

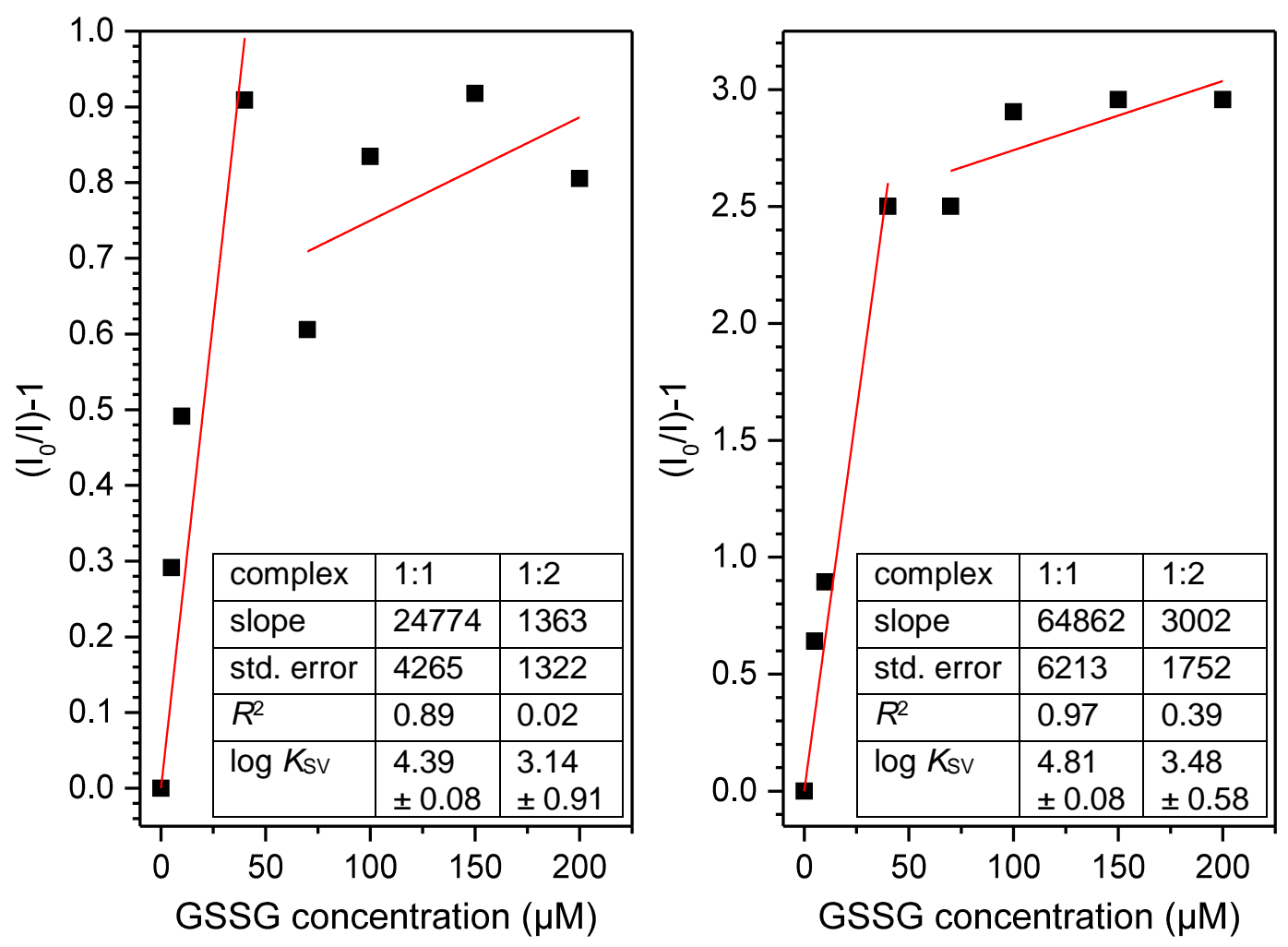

Figure S6. Stern-Volmer-Plots of the ligand titration series for determination of the association constant at $\mathrm{pH} 3$, directly obtained from TRLFS data (left) and after PARAFAC refinement (right), with the red lines representing linear fits and the tables stated with the plots reporting their analyses.

The data point distribution suggests grouping as two data sets. Accordingly, on account of lower and higher ligand concentrations the formation of two complexes is assumed. By means of PARAFAC the data could be significantly refined. In both cases, however, the data tentatively assigned to the 1:2 complex show a large scattering and hence a large error value. Therefore, these data were not considered.

PARAFAC was performed according to the description by Drobot et al. ${ }^{6}$ and related references cited therein. All Toolboxes were used with MATLAB R2018.

Calculation of $\log \beta_{131}$ (according to the notation $\log \beta_{p q r}$ for the complex composed of $\mathrm{M}_{p} \mathrm{H}_{q} \mathrm{~L}_{r}$ ) was according to the reaction $\mathrm{UO}_{2}{ }^{2+}+\mathrm{H}_{3} \mathrm{GSSG}^{-} \rightarrow \mathrm{UO}_{2}\left(\mathrm{H}_{3} \mathrm{GSSG}\right)^{+}$with $\log \beta_{131}=\log K+$ $\log \beta_{031}$, the latter meaning the cumulative protonation constant for $\mathrm{H}_{3} \mathrm{GSSG}^{-}$calculated from the sum of GSSG's stepwise protonation constants (cf. Table 1):

$\log \beta_{131}=4.81 \pm 0.08+[(9.53 \pm 0.02)+(8.83 \pm 0.01)+(3.85 \pm 0.01)]=27.02 \pm 0.12$. 
A)

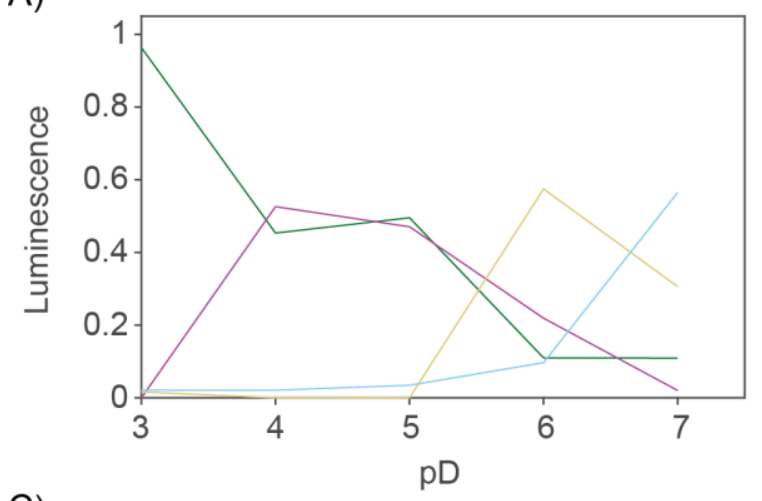

C)

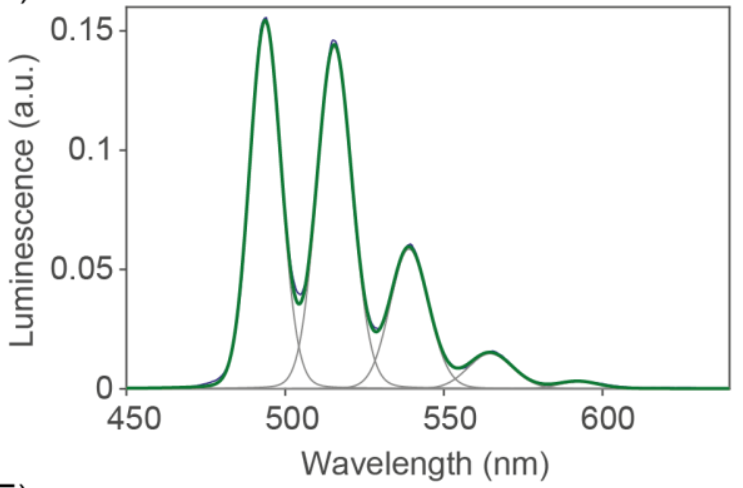

E)

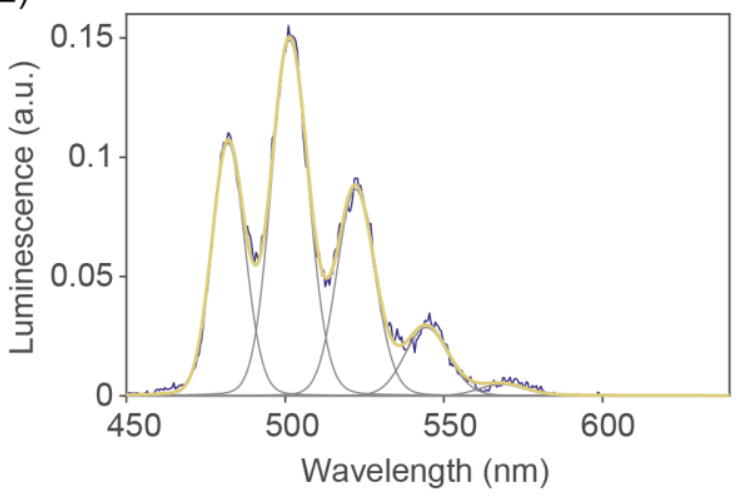

B)

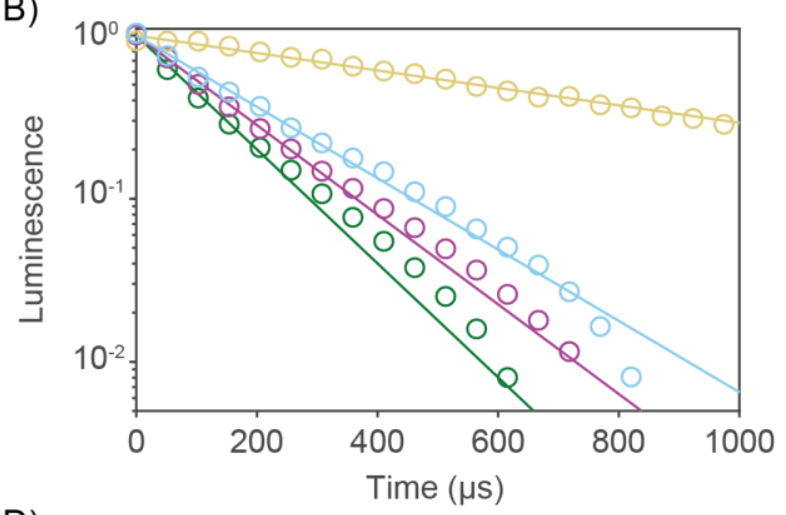

D)

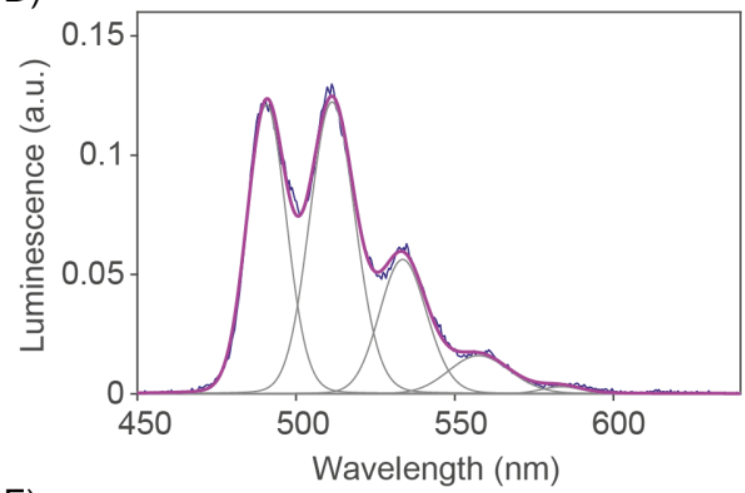

F)

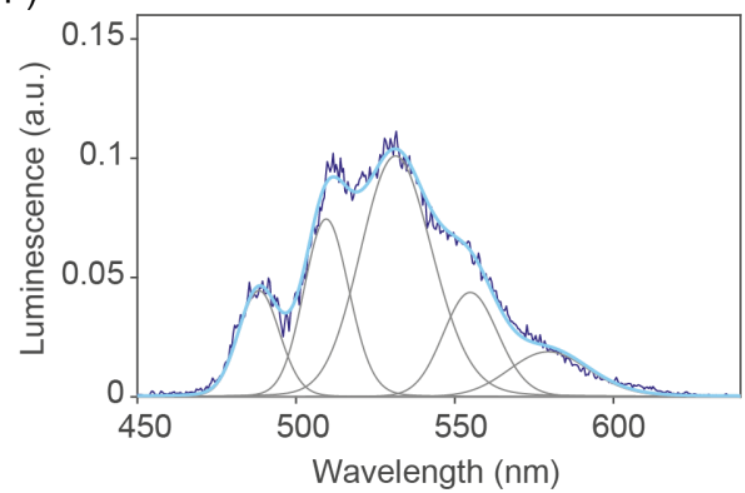

Figure S7. PARAFAC deconvolution of the cryo-TRLFS data of the GSSG-Uranyl(VI) supernatant system in the pD range from 3 to 7 . The color code is the same for all subfigures. Species distribution as shown in the main text (A) and corresponding luminescence decays (B). Individual PARAFAC emission spectra and their deconvolution is shown in $\mathrm{C}$ through $\mathrm{F}$. The raw PARAFAC spectra are shown in dark blue, the transitions into the vibrational levels depicted in gray, and their sum is given in the respective species-associated color. Since TRLFS was performed at cryogenic conditions (153 K), hot-bands were not included. 
A)

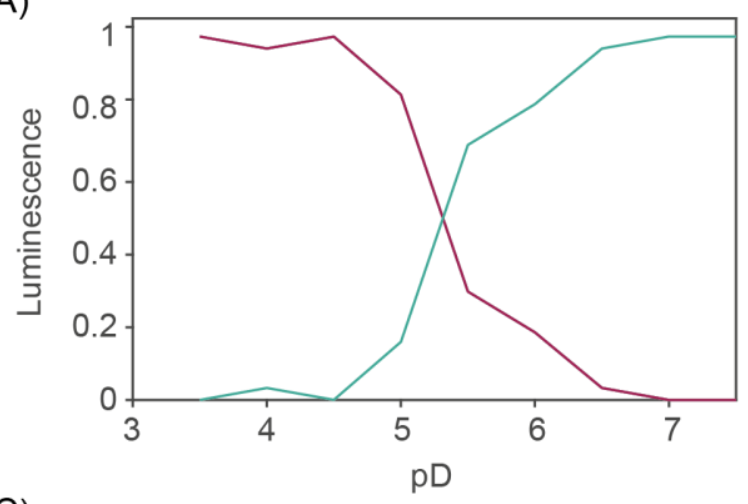

C)

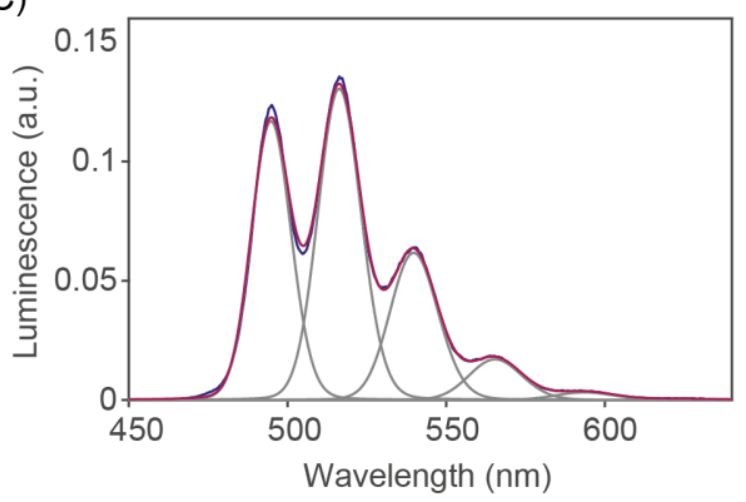

B)

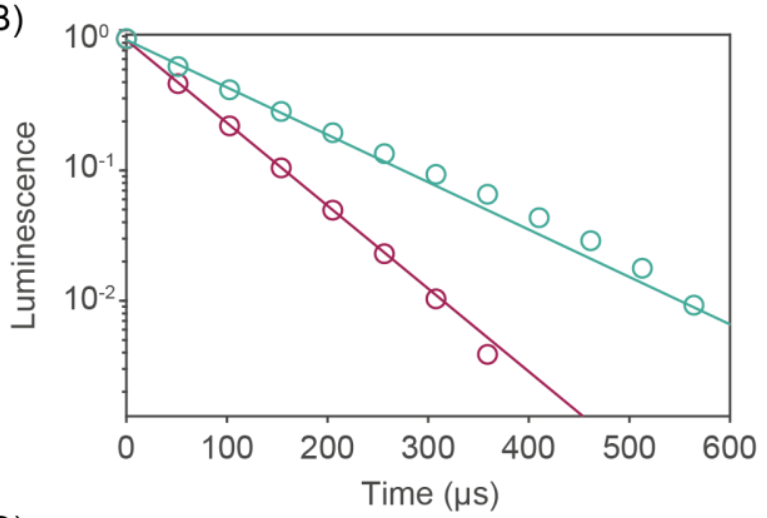

D)

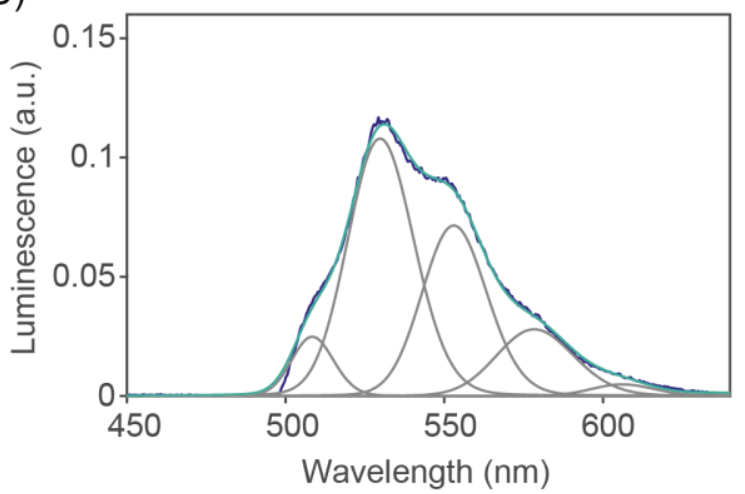

Figure S8. PARAFAC deconvolution of the cryo-TRLFS data of the GSSG-Uranyl(VI) precipitate system in the pD range from 3 to 7 . The color code is the same for all subfigures. Species distribution as shown in the main text (A) and corresponding luminescence decays (B). Individual PARAFAC emission spectra and their deconvolution is shown in $\mathrm{C}$ and D. The raw PARAFAC spectra are shown in dark blue, the transitions into the vibrational levels depicted in gray, and their sum is given in the respective species-associated color. Since TRLFS was performed at cryogenic conditions (153 K), hot-bands were not included. 


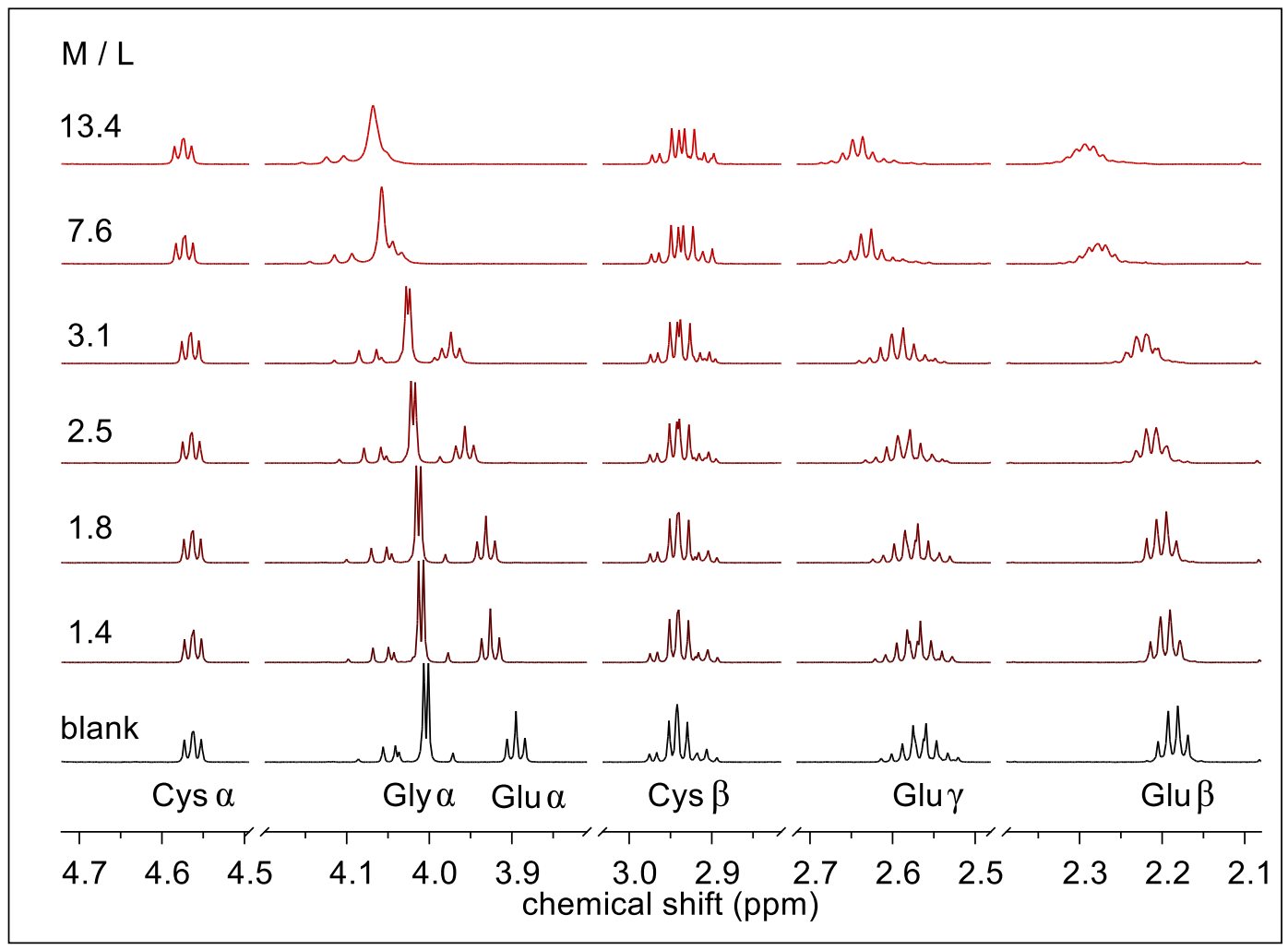

Figure S9. ${ }^{1} \mathrm{H}$ NMR spectra of $6.7 \mathrm{mM} \mathrm{GSH}$ and varying U(VI) contents at pD 2. The re-determined M/L is stated with the spectra. For clarity, only parts of the spectra are shown.

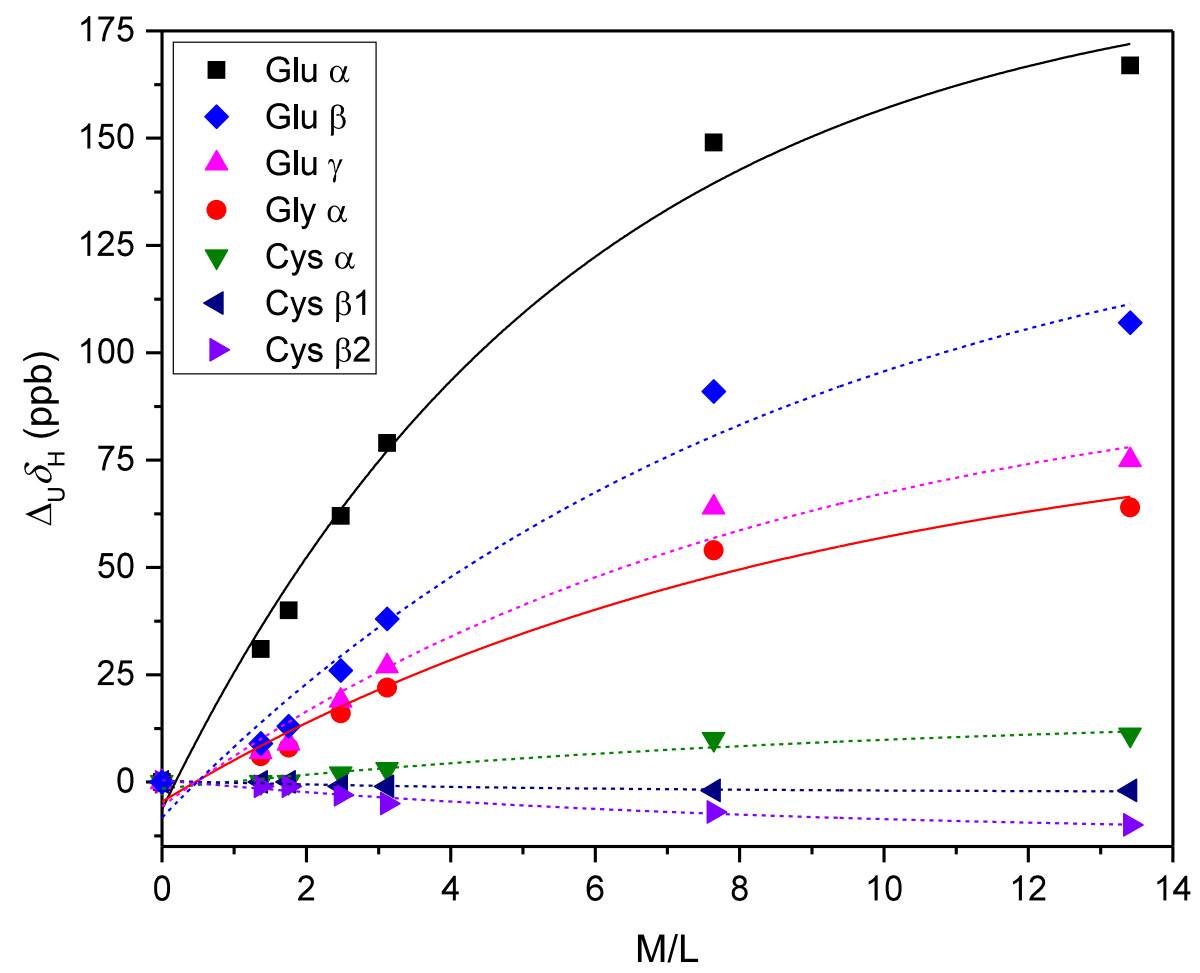

Figure S10. U(VI)-induced ${ }^{1} \mathrm{H}$ chemical shift changes $\left(\Delta_{\mathrm{U}} \delta_{\mathrm{H}}\right)$ as a function of M/L obtained from spectra of $6.7 \mathrm{mM}$ GSH and varying U(VI) content at pD 2 according to Figure S9, with concentrations re-determined by TOC and ICPMS analyses. The lines represent asymptotic fits. 
The magnitude of the signals' shift increases with increasing [U(VI)] relative to the GSH blank solution. Alike GSSG, GSH exhibits interaction with $\mathrm{UO}_{2}{ }^{2+}$ already at $\mathrm{pD} 2$, and the ligand exchange reaction is fast on the NMR timescale, hence only molar fraction weighted averaged signals can be observed. However, the exchange rate decreases with increasing [U(VI)] and, therefore, the line width, $\Delta v_{1 / 2}$, increases - most notably for the Glu $\alpha$ and Gly $\alpha$ signals. Consequently, with increasing $\mathrm{U}(\mathrm{VI})$ contents, the proportion of U(VI)-bound GSH increases and the apparent signals progressively exhibit properties of the complex's signals. As can be seen, $\Delta_{\mathrm{U}} \delta_{\mathrm{H}}$ is larger for the Glu $\alpha$ than for the Gly $\alpha$ signal under these $\mathrm{pD}$ conditions. In fact, at pD 2 the Glu $\mathrm{COOH}$ is already ionized to about $33 \%$ whereas the Gly $\mathrm{COOH}$ is deprotonated only by about $5 \%$, cf. Figure S2. In light of the small fraction of deprotonated Gly carboxylate, the observed Gly $\alpha \Delta_{\mathrm{U}} \delta_{\mathrm{H}}$ values are remarkable in comparison to those of Glu $\alpha$, cf. solid lines in Figure S10, see above. The diagram also discloses that the $\Delta_{\mathrm{U}} \delta_{\mathrm{H}}$ values can be fitted by asymptotic curves, especially for the signals of both the Glu and Gly moiety. This feature is to be expected, whereupon the asymptote represents the maximum $\mathrm{U}(\mathrm{VI})$-induced chemical shift, i.e., upon even further increase of M/L the signals remain unaffected for the considered binding site is saturated in the whole ensemble of probed molecules.

Two further series of varying M/L for $\mathrm{pD} 5$ and $\mathrm{pD} 8$ were investigated by ${ }^{1} \mathrm{H}$ NMR (Figures $\mathrm{S} 11$ and S12, below) with spectra portraying the samples' supernatants owing to precipitate formation. Briefly, the pD 5 spectra are very similar among one other with maximum $\Delta_{\mathrm{U}} \delta_{\mathrm{H}}$ of $10 \mathrm{ppb}$ for Glu $\alpha$ since increasing $\mathrm{M} / \mathrm{L}$ causes $\mathrm{U}(\mathrm{VI})-\mathrm{GSH}$ complex precipitation rather than increasing contents of aqueous U(VI)-GSH species. The $\mathrm{pD} 8$ spectra reveal virtually no $\Delta_{\mathrm{U}} \delta_{\mathrm{H}}$ in dependence of M/L. However, although again precipitates were formed, GSH removal from solution was much lower compared to the pD 5 samples. 


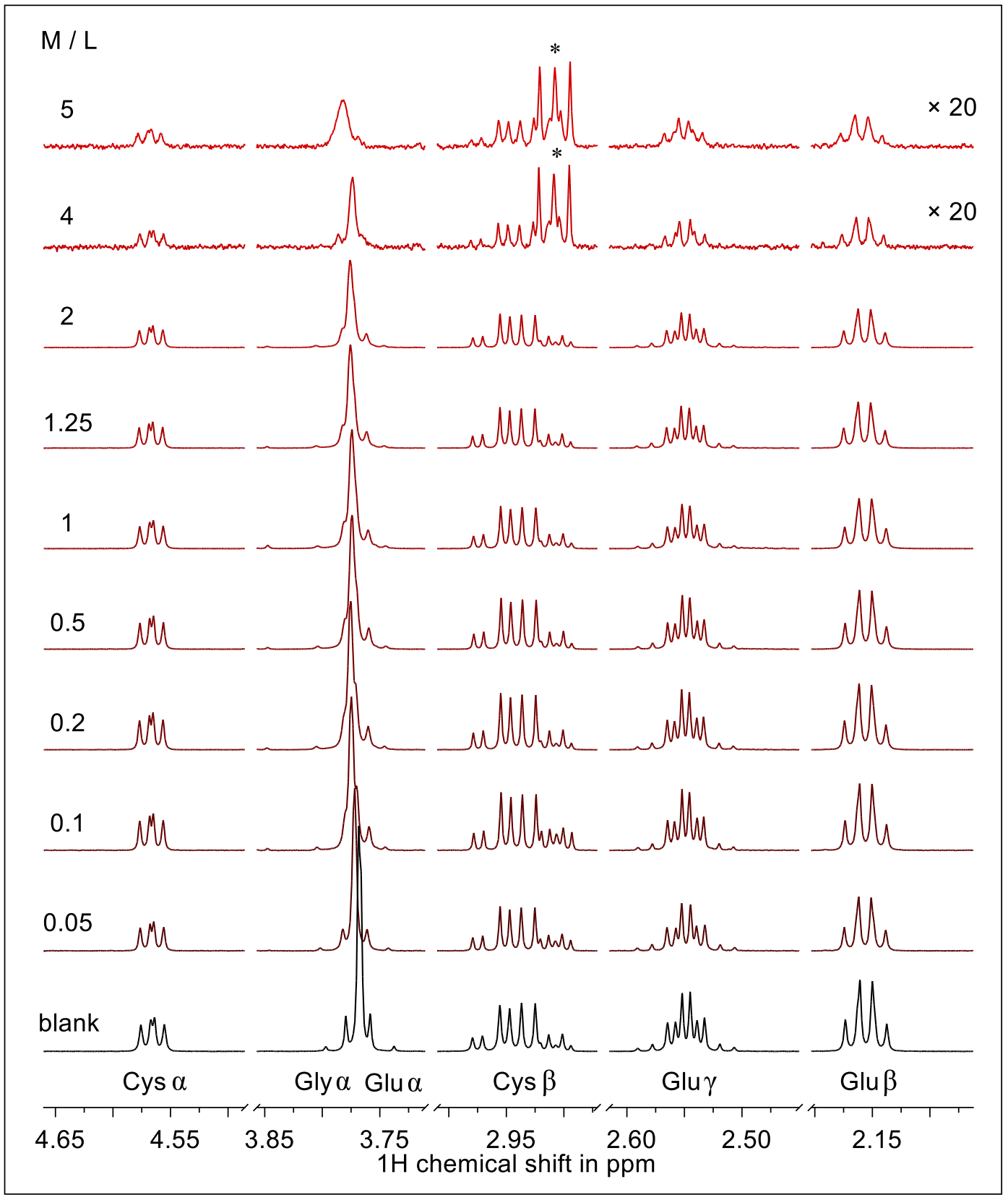

Figure S11. ${ }^{1} \mathrm{H}$ NMR spectra of $6.7 \mathrm{mM}$ GSH and varying U(VI) content (increasing from bottom to top) at pD 5. The initial M/L is stated with the spectra. Note that only parts of the spectra are shown for clarity; the top two spectra are enhanced by a factor of $20 ;(*)$ indicates the DSS $\left(-\mathrm{CH}_{2}-\mathrm{SO}_{3}{ }^{-}\right)$signal.

The remaining GSH contents (or in other words: $\mathrm{S} / \mathrm{N}$ ) for the top two spectra is such low owing to precipitate formation that upon enhancing the vertical scale one of DSS's signals $\left(-\mathrm{CH}_{2}-\mathrm{SO}_{3}{ }^{-}\right)$ (sodium 2,2-dimethyl-2-silapentane-5-sulfonate; used as internal standard) stands out. 


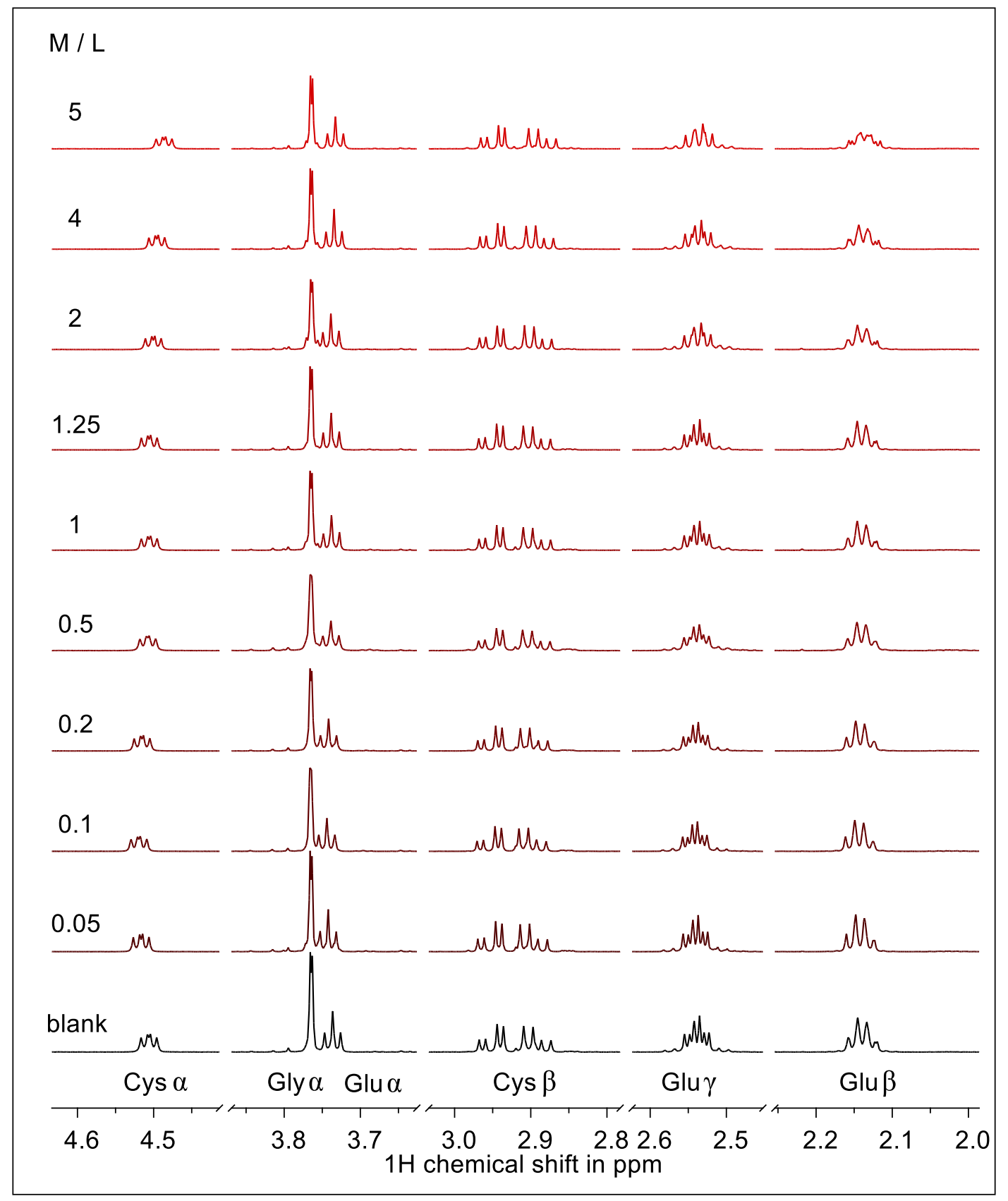

Figure S12. ${ }^{1} \mathrm{H}$ NMR spectra of $6.7 \mathrm{mM}$ GSH and varying U(VI) content (increasing from bottom to top) at $\mathrm{pD} 8$. The initial $\mathrm{M} / \mathrm{L}$ is stated with the spectra. Note that only parts of the spectra are shown for clarity. 


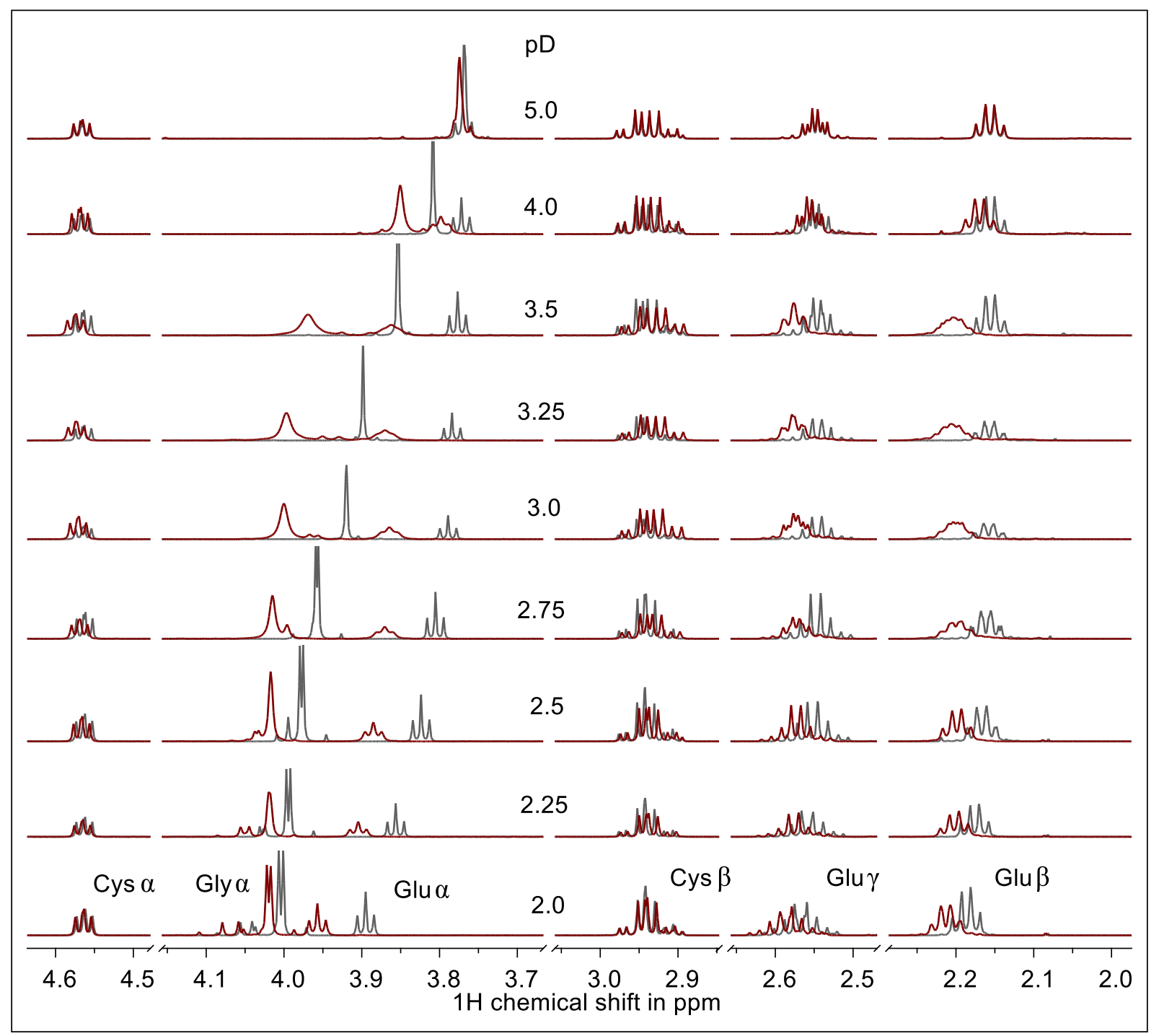

Figure S13. ${ }^{1} \mathrm{H}$ NMR spectra of $6.7 \mathrm{mM} \mathrm{GSH}$ blanks (grey) and U(VI) containing samples with initial $\mathrm{M} / \mathrm{L}=0.5$ (red) in the pD range 2-5, corresponding to the $\Delta_{\mathrm{U}} \delta_{\mathrm{H}} v s$. pD plot in Figure S17 (left). For clarity, only parts of the spectra are shown. 


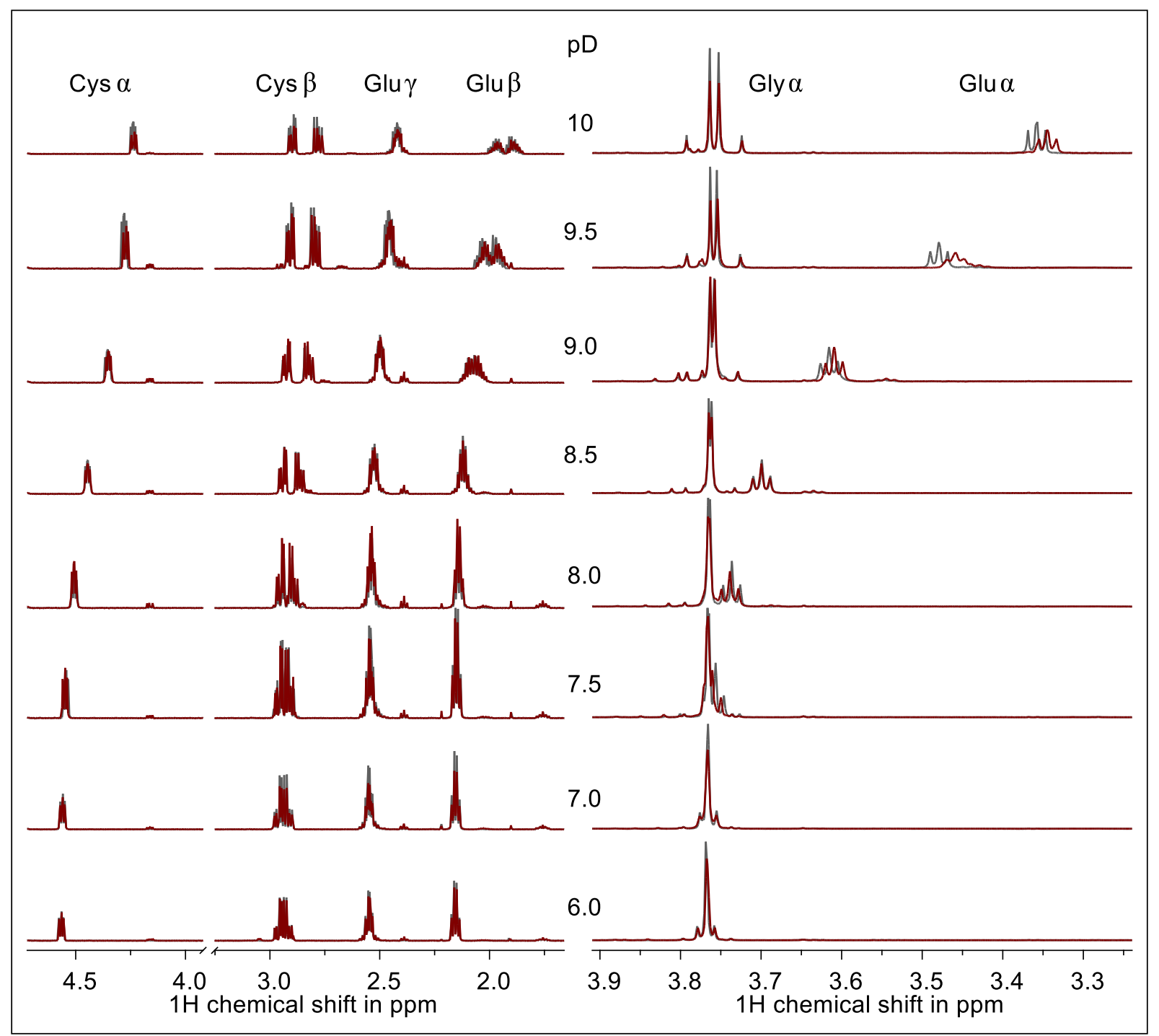

Figure S14. ${ }^{1} \mathrm{H}$ NMR spectra of $6.7 \mathrm{mM}$ GSH blanks (grey) and U(VI) containing samples with initial M/L $=0.5$ (red) in the pD range 6-10. For clarity, the region between 3.3 and $3.9 \mathrm{ppm}$ is omitted on the left and enlarged on the right. 


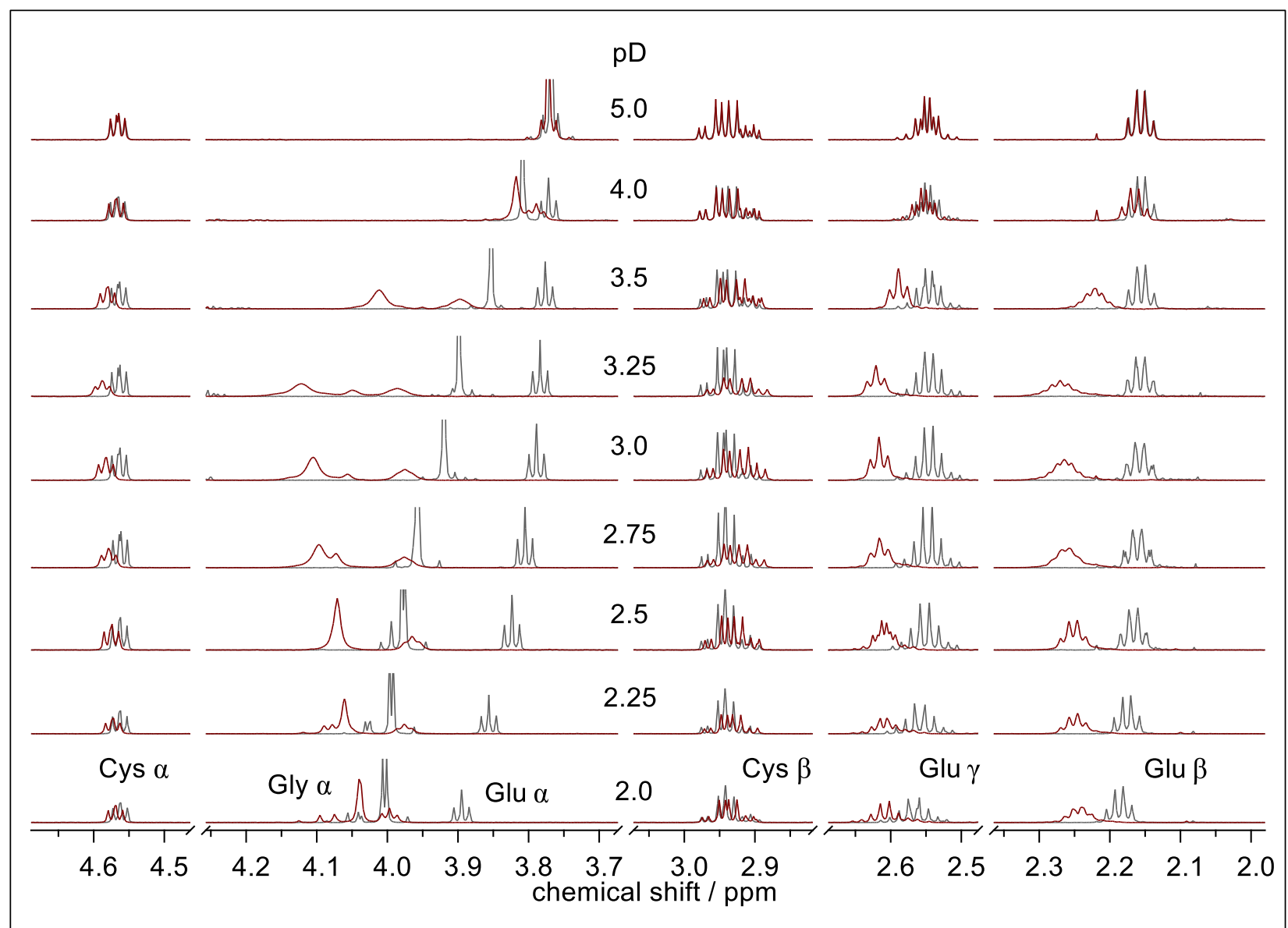

Figure S15. ${ }^{1} \mathrm{H}$ NMR spectra of $6.7 \mathrm{mM} \mathrm{GSH}$ blanks (grey) and U(VI) containing samples with initial M/L = 2 (red) in the $\mathrm{pD}$ range 2-5, corresponding to the $\Delta_{\mathrm{U}} \delta_{\mathrm{H}} v s$. pD plot in Figure S17 (right). For clarity, only parts of the spectra are shown. 


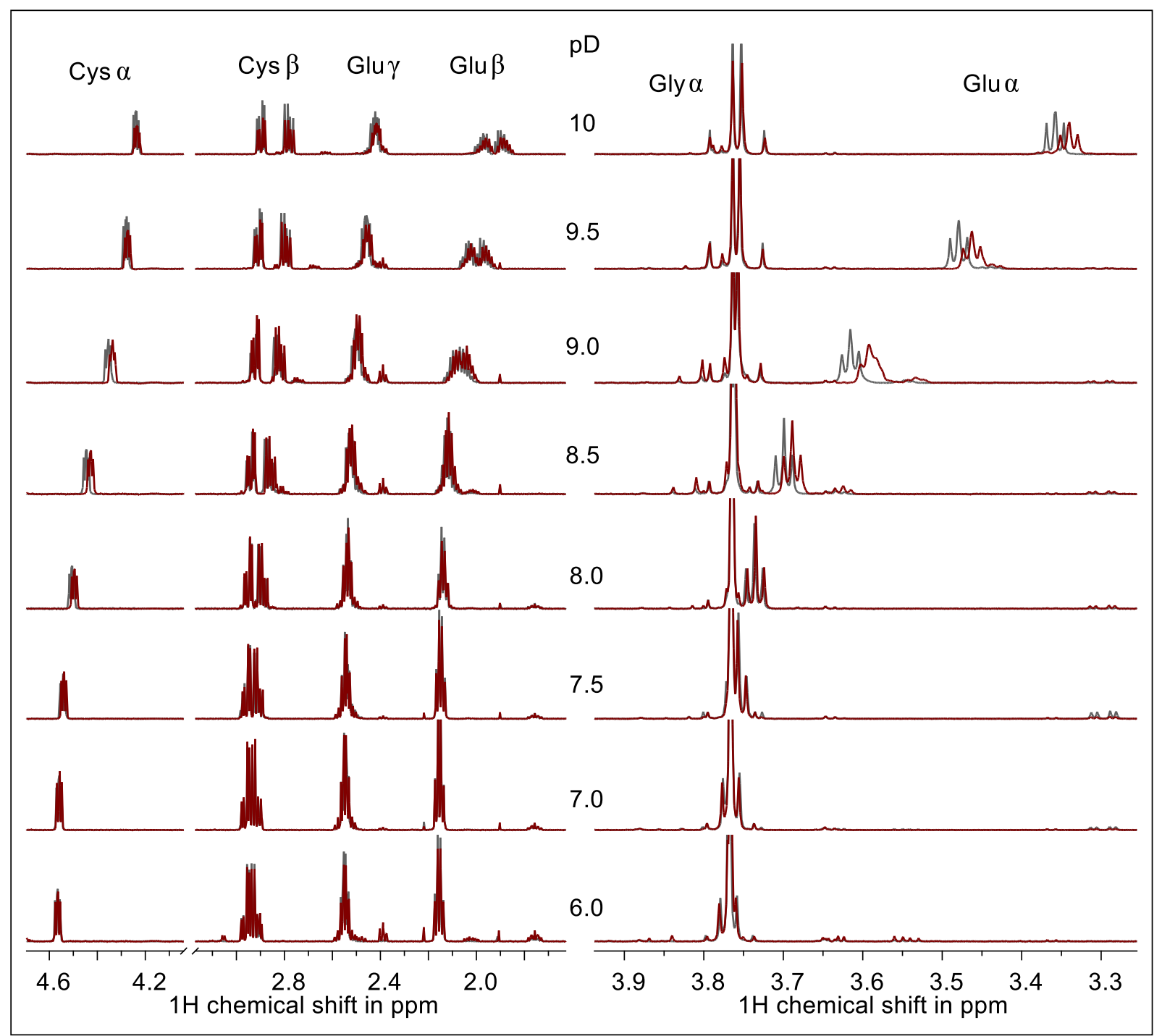

Figure S16. ${ }^{1} \mathrm{H}$ NMR spectra of $6.7 \mathrm{mM}$ GSH blanks (grey) and U(VI) containing samples with initial M/L = 2 (red) in the pD range 6-10. For clarity, the region between 3.3 and $3.9 \mathrm{ppm}$ is omitted on the left and enlarged on the right. 


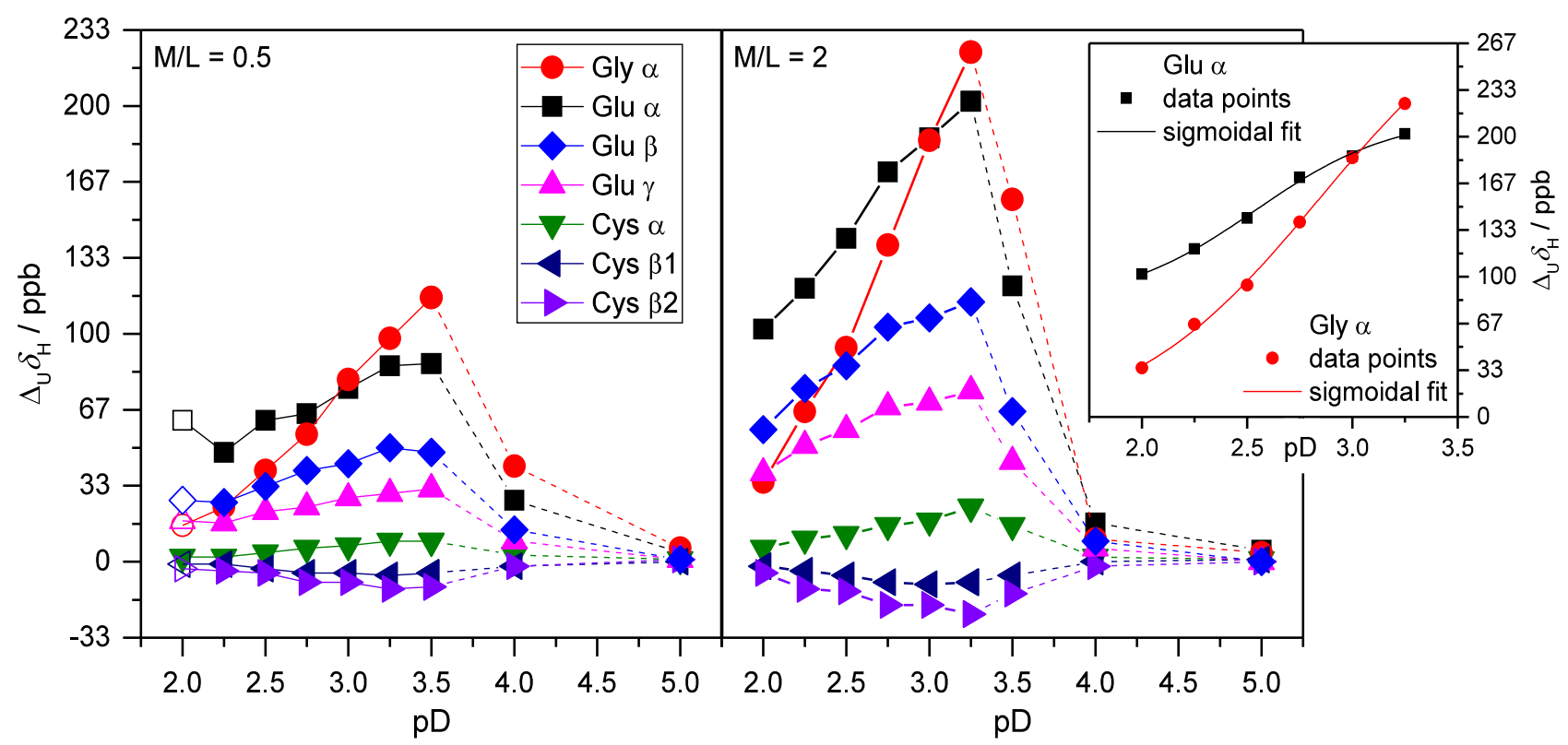

Figure S17. U(VI)-induced ${ }^{1} \mathrm{H}$ chemical shift changes, $\Delta_{\mathrm{U}} \delta_{\mathrm{H}}$, as a function of pD obtained from spectra $6.7 \mathrm{mM}$ in GSH, and initial M/L of 0.5 (left) and 2 (right), with lines drawn for better visualization. The inset shows sigmoidal fits to the corresponding Glu $\alpha$ and Gly $\alpha \mathrm{M} / \mathrm{L}=2$ data points. Note the $\mathrm{M} / \mathrm{L}=0.5 \mathrm{pD} 2$ data points (open symbols) are considered as outliers.

The GSH-related spectra in Figures S13 - S16 can be regarded as pD-titration series in the presence of U(VI), thereby examining the metal ion's pD-dependent impact on the functional groups. The corresponding graphs in Figure S17 illustrate the pD-dependent accessibility to and capability of $\mathrm{U}(\mathrm{VI})$ complexation by the two sorts of carboxyl groups. That is, because of its low $\mathrm{p} K_{\mathrm{a}}$ the Glu carboxyl can bind - are accessible for - U(VI) already at much lower pD values. Accordingly, at low $\mathrm{pD}\left|\Delta_{\mathrm{U}} \delta_{\mathrm{H}}\right|$ are largest for signals of Glu $\alpha / \beta / \gamma$, with the magnitude attenuating corresponding to the respective hydrogen's distance to the binding site, however, their 'curves' (black, blue, and pink, respectively, Figure S17) are of comparable slope. Complementary, the Gly carboxyl is less acidic (higher $\mathrm{p} K_{\mathrm{a}}$ ), that is, more basic, and hence less accessible owing to competition between $\mathrm{U}(\mathrm{VI})$ and $\mathrm{H}^{+} / \mathrm{D}^{+}$for the binding site, consequently showing smaller $\left|\Delta_{\mathrm{U}} \delta_{\mathrm{H}}\right|$ at low $\mathrm{pD}$. However, as of $\mathrm{pD}$ values in the order of Gly's $\mathrm{p} K_{\mathrm{a}}$, i.e., commencing deprotonation, U(VI) shows preferred binding to this site. 
Table S2. Obtained fitting parameters for the sigmoidal dose-response-fits shown as inset in Figure S17 according to

\begin{tabular}{ccc}
\multicolumn{3}{c}{$y=\mathrm{A} 1+(\mathrm{A} 2-\mathrm{A} 1) /\left(1+10^{\left(\log \left(x_{0}-x\right)\right) \cdot p}\right)$} \\
\hline parameter & Glu $\alpha$ & Gly $\alpha$ \\
\hline A1 & $50.00 \pm 7.82$ & $4.43 \pm 17.81$ \\
A2 & $127.97 \pm 5.64$ & $188.50 \pm 37.87$ \\
$x_{0}$ & $2.551 \pm 0.054$ & $2.827 \pm 0.123$ \\
$p$ & $0.973 \pm 0.320$ & $1.396 \pm 0.339$ \\
$R^{2}$ & 0.99485 & 0.99662 \\
\hline \hline
\end{tabular}

$\mathrm{A} 1$ and $\mathrm{A} 2$ can be seen as bottom and top asymptote, $x_{0}$ as the inflection point, and $p$ as the hill slope.

Correspondingly obtained parameters from sigmoidal dose-response-fitting (cf. inset in Figure S17 and Table S2) quantify these properties by means of both the inflection point and the Hill slope, with values calculated as $2.55 \pm 0.06$ and $2.83 \pm 0.13$, and $0.97 \pm 0.32$ and $1.40 \pm 0.34$ for Glu $\alpha$ and Gly $\alpha$, respectively. The former are calculated in $\mathrm{pD}$ units and represent those $\mathrm{pD}$ values where the concentration of free and U(VI)-bound carboxyl are equal, reflecting Gly carboxyl's higher capability in U(VI) complexation. That is, for the given conditions, one half of the Gly carboxyl is bound to $\mathrm{U}(\mathrm{VI})$ at $\mathrm{pD} 2.83$, a value remarkably below its $\mathrm{p} K_{\mathrm{a}}(\approx 3.3)$, whereas half of the Glu carboxyl is $\mathrm{U}(\mathrm{VI})$-bound at $\mathrm{pD} 2.55$, slightly above its $\mathrm{p} K_{\mathrm{a}}(\approx 2.3)$. Gly carboxyl's higher capability is reflected by larger $\Delta \Delta_{\mathrm{U}} \delta_{\mathrm{H}}$ resulting in the steeper 'curve' (red, Figure S17), corresponding to the larger Hill slope value mirroring the higher $\mathrm{pH}$-dependent sensitivity (response) on U(VI)complexation. 
Table S3. Band assignment ${ }^{a}$ and interpretation of the IR spectra shown in Figure 6, corresponding to washed and lyophilized precipitates obtained from centrifuged suspensions of $150 \mathrm{mM} \mathrm{GSSG}$ and $7.5 \mathrm{mM} \mathrm{U}(\mathrm{VI})$ for pD 2-8.

\begin{tabular}{|c|c|c|}
\hline$\tilde{v}\left(\mathrm{~cm}^{-1}\right)$ & assignment & structure/fragment \\
\hline 3560 & amide $\mathrm{A}$ & amide $\mathrm{NH}$ stretch \\
\hline 3430 & $v(\mathrm{OH})$ & water (coordinating U) \\
\hline 3250 & amide $\mathrm{A}$ & amide $\mathrm{NH}$ stretch \\
\hline 3061 & amide $\mathrm{B}$ & amide $\mathrm{NH}$ stretch \\
\hline 2972 & $v_{\mathrm{as}}\left(\mathrm{CH}_{2}, \mathrm{sp}^{3}\right)$ & methylene groups \\
\hline 2931 & $v_{\mathrm{s}}\left(\mathrm{CH}_{2}, \mathrm{sp}^{3}\right)$ & methylene groups \\
\hline 2865 & $v_{\mathrm{s}}\left(\mathrm{CH}, \mathrm{sp}^{3}\right)$ & $\mathrm{C}(\alpha)-\mathrm{H}$ \\
\hline 1736 & $v_{\mathrm{as}}(\mathrm{COO})$ & Gly $\mathrm{COOH}$ (pD 2 and 4) \\
\hline 1682 & amide I & Glu CO stretch \\
\hline 1654 & amide I & Cys CO stretch \\
\hline 1637 & $v_{\mathrm{as}}(\mathrm{COO})$ & COOU (Glu) \\
\hline 1592 & $v_{\mathrm{as}}(\mathrm{COO})$ & $\mathrm{COO}^{-}$ \\
\hline 1568 & amide II & CO-NH Cys-Gly \\
\hline 1578 & $v_{\mathrm{as}}(\mathrm{COO})$ & COOU (Gly) \\
\hline 1549 & amide II & CO-NH Glu-Cys \\
\hline 1472 & $v_{\mathrm{s}}(\mathrm{COO})$ & COOU (Gly) \\
\hline 1456 & $\delta\left(\mathrm{CH}_{2}\right)$ & methylene groups \\
\hline 1396 & $v_{\mathrm{s}}(\mathrm{COO})$ & $\mathrm{COO}^{-}$ \\
\hline 1375 & $v_{\mathrm{s}}(\mathrm{COO})$ & COOU (Glu) \\
\hline 1365 & $\delta\left(\mathrm{CH}_{2}\right)$ & Gly methylene group \\
\hline 1352 & $\delta\left(\mathrm{CH}_{2}\right)$ & Glu methylene groups \\
\hline 1315 & $\delta\left(\mathrm{CH}_{2}\right)$ & Gly methylene group \\
\hline $916-906$ & $v_{\mathrm{as}}(\mathrm{O}=\mathrm{U}=\mathrm{O})$ & uranyl units \\
\hline 867 & $\delta(\mathrm{N}-\mathrm{C}-\mathrm{C})$ & Gly residue \\
\hline 797 & $\delta(\mathrm{COO})$ & carboxyl \\
\hline
\end{tabular}

${ }^{a}$ Assignment according to refs. 7 and 8. v, stretching; as, antisymmetric; s, symmetric; $\delta$, deformation. 

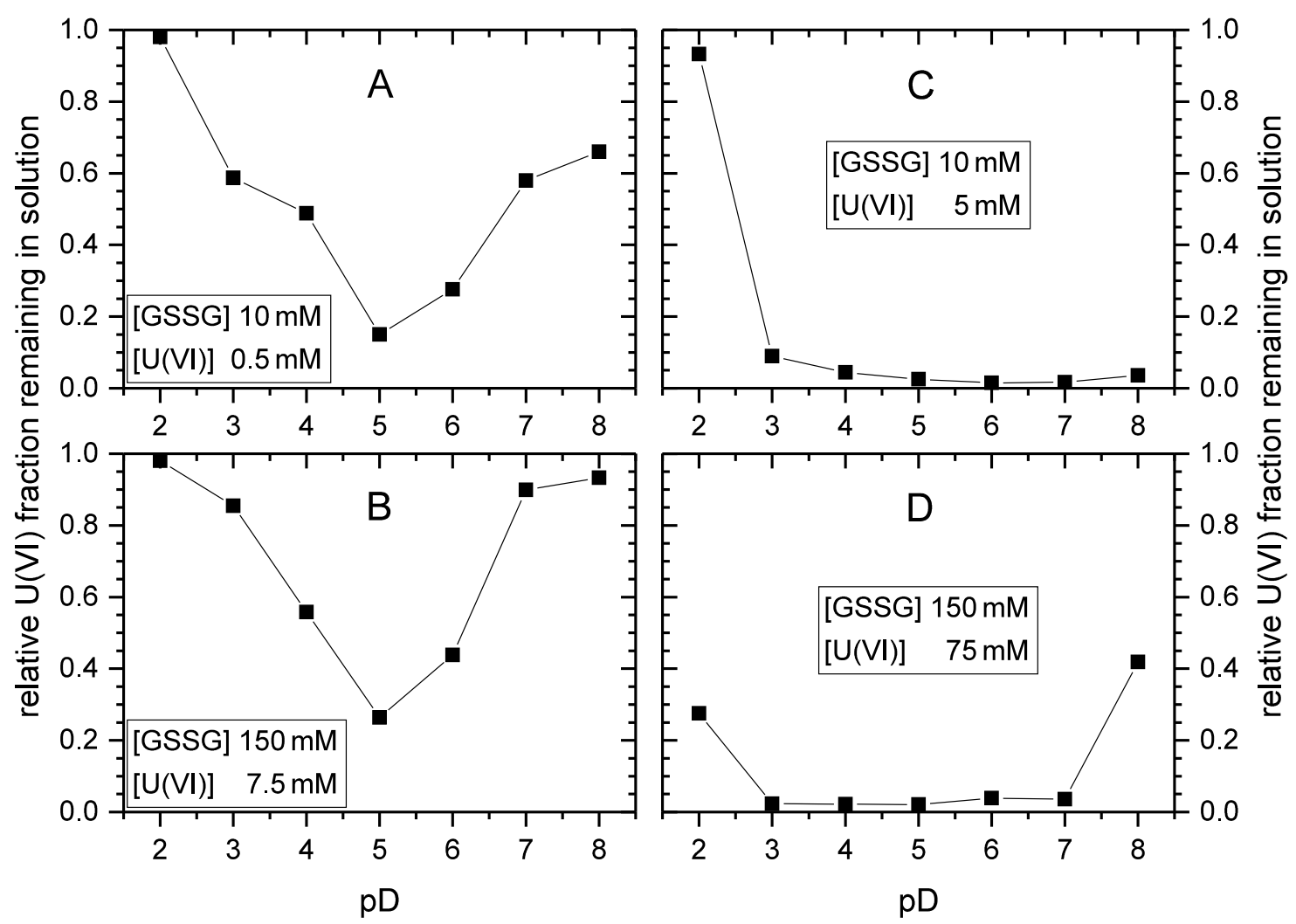

Figure S18. U(VI) fraction remaining dissolved in solution for different sample series of varying both initial GSSG concentration (A and C $10 \mathrm{mM}, \mathrm{B}$ and D $150 \mathrm{mM}$, respectively) and GSSG/U(VI) ratio (20 for A and B, 2 for C and $\mathrm{D}$, respectively).

For both series of 20-fold GSSG excess (A and B) and irrespective of absolute [GSSG], the least $\mathrm{U}(\mathrm{VI})$ contents remain in solution at $\mathrm{pD} \approx 5$ when the predominating GSSG species bears a net charge of -2 . Upon further increasing $\mathrm{pD}$ less precipitate forms, corresponding to higher $\mathrm{U}(\mathrm{VI})$ fraction remaining in solution according to the predominance of charged (anionic) and, thus, soluble ternary (polynuclear) U(VI) GSSG hydroxo species. Sample series with only twofold excess in GSSG (C and D) reveal very little dissolved U(VI) as of pD 3. Accordingly, the investigated solutions can be considered as virtually saturated regarding U(VI)-GSSG complexes 

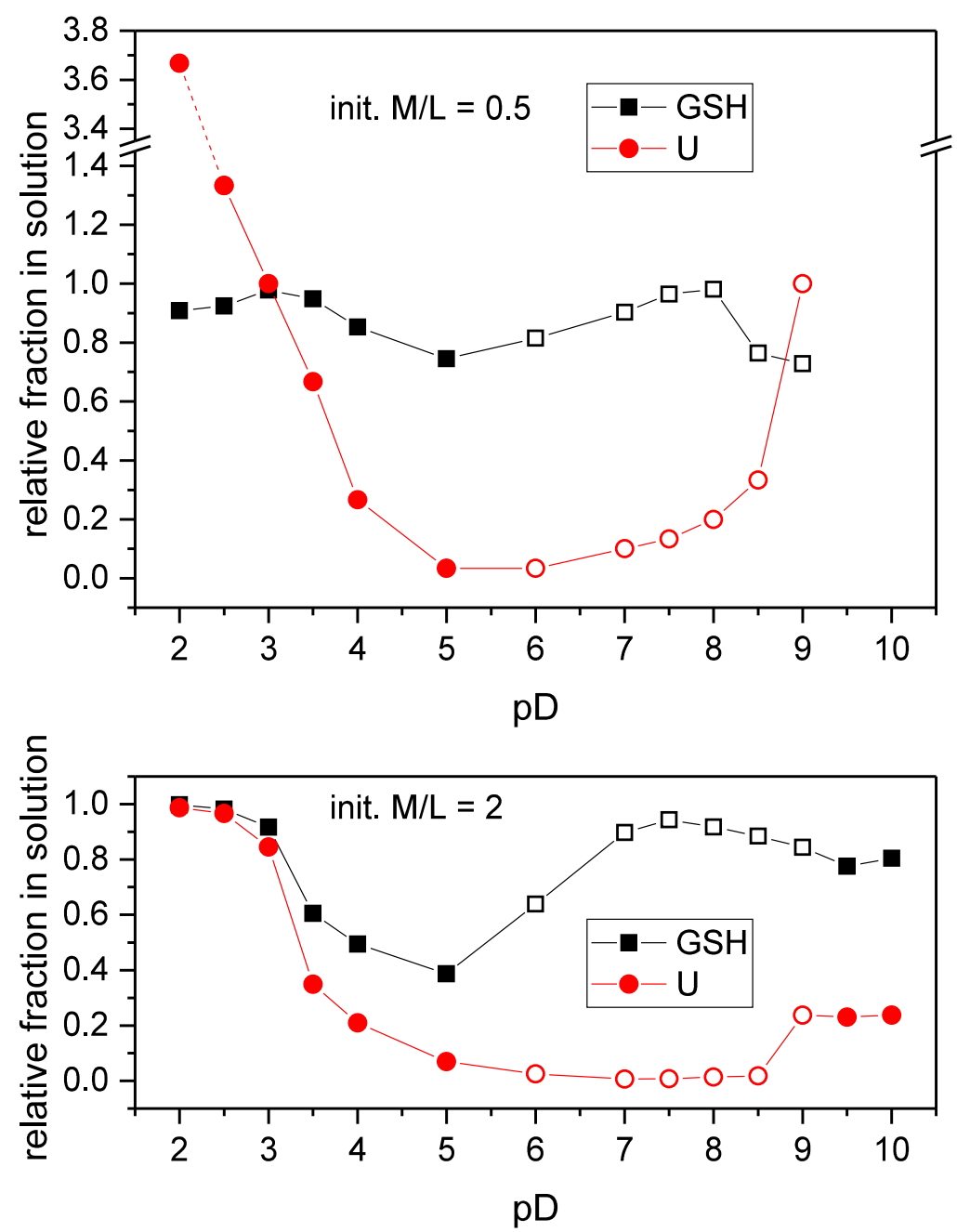

Figure S19. GSH and uranium contents remaining in solution as determined by TOC and ICP-MS analyses for sample series of initial $6.7 \mathrm{mM} \mathrm{GSH}$ and either $13.3 \mathrm{mM} \mathrm{U}(\mathrm{VI})$ (bottom) or $3.3 \mathrm{mM} \mathrm{U}(\mathrm{VI})$ (top). Note the relative scale on the $y$-axis with GSH and $\mathrm{U}(\mathrm{VI})$ contents normalized by their initial concentrations, respectively. Lines are drawn for better visualization.

The data result from TOC and ICP-MS analyses and were normalized regarding initial [U(VI)] and [GSH], respectively. That is, both plots refer to the same initial $[\mathrm{GSH}]$, however, with the $\mathrm{M} / \mathrm{L}=0.5$ series containing only one quarter of the initial $[\mathrm{U}(\mathrm{VI})]$ as for $\mathrm{M} / \mathrm{L}=2$. The former thus shows much less GSH removal. Open symbols refer to the $\mathrm{pD}$ range for which a redox reaction ${ }^{a}$ was observed. TOC analyses are expressed as GSH equivalents, correspondingly including oxidized GSH, i.e., GSSG. For the M/L = 0.5 series pD 2 sample accidentally a much higher [U(VI)] was applied during preparation, therefore the $\mathrm{pD} 2$ data points in the $\Delta_{\mathrm{U}} \delta_{\mathrm{H}} v s . \mathrm{pD}$ plot (Figure S17, left, open symbols) are considered as outliers. All other data points are reliable and in accordance with those of the $\mathrm{M} / \mathrm{L}=2$ data set, though..

${ }^{a}$ Note that the GSH-U(VI) investigations were subject of comprehensive complexation and redox reaction studies with results of the former section presented here, and the results of the latter section, comprising formation of hyperstoichiometric $\mathrm{UO}_{2+x}$ phases and continued redox reaction in the wet solid phase after centrifugation of the initially obtained sample suspensions, published quite recently. ${ }^{9}$ 


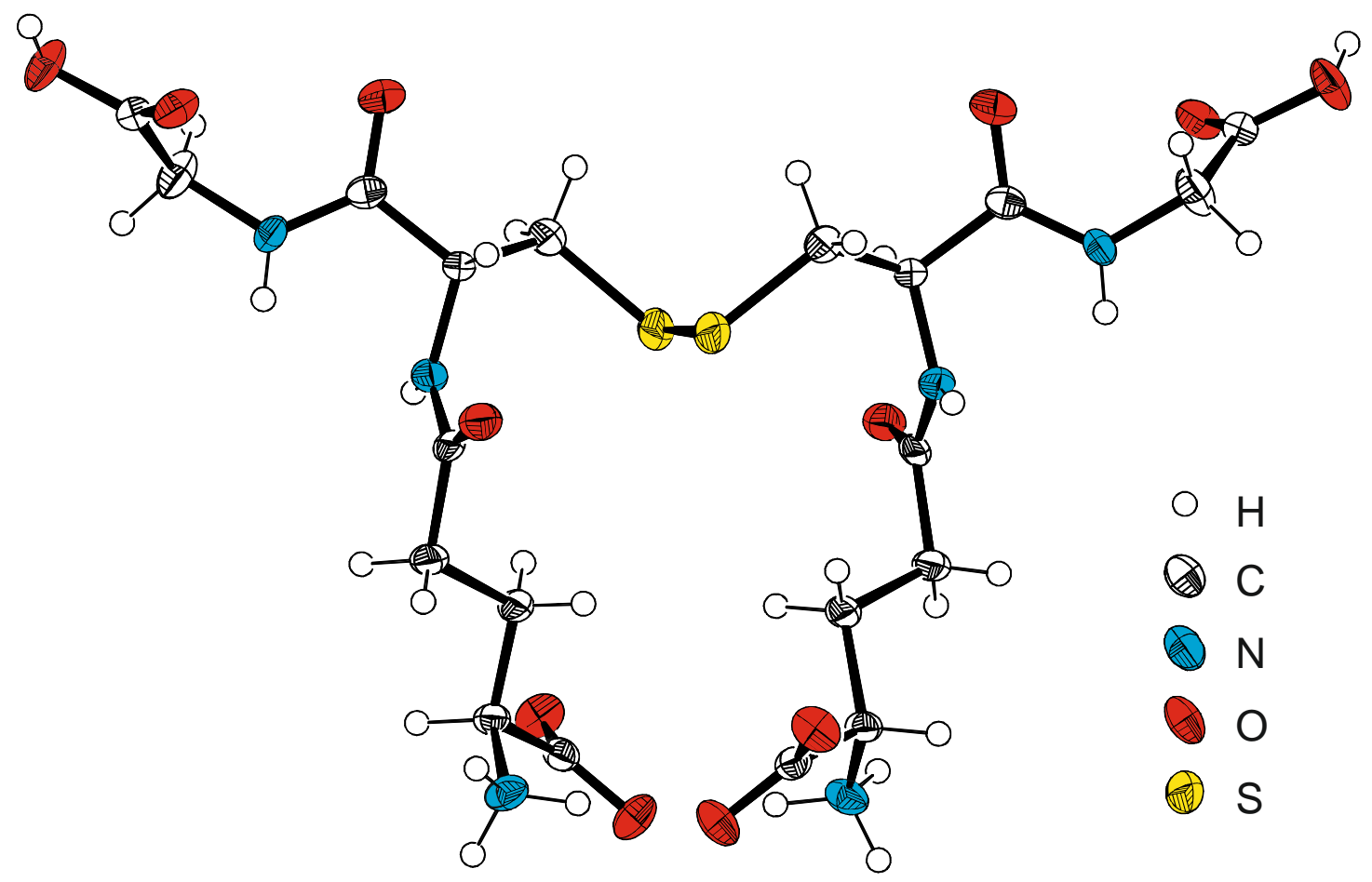

Figure S20. Crystal structure representation of GSSG obtained at pH 3 (adapted from Kretzschmar et al., ${ }^{10}$ CCDC no. 981311). 


\section{References}

1. Wolery, T. J. EQ3/6: a software package for geochemical modeling of aqueous systems: package overview and installation guide (version 7.0), Lawrence Livermore National Laboratory, Livermore, CA, 1992.

2. Guillaumont, R.; Fanghänel, T.; Fuger, J.; Grenthe, I.; Neck, V.; Palmer, D. A.; Rand, M. H.; OECD/NEA, Update on the Chemical Thermodynamics of Uranium, Neptunium, Plutonium, Americium and Technetium. Elsevier: Amsterdam, 2003.

3. Alderighi, L.; Gans, P.; Ienco, A.; Peters, D.; Sabatini, A.; Vacca, A., Hyperquad simulation and speciation (HySS): a utility program for the investigation of equilibria involving soluble and partially soluble species. Coord. Chem. Rev. 1999, 184, 311-318.

4. Noszál, B.; Szakács, Z., Microscopic Protonation Equilibria of Oxidized Glutathione. J. Phys. Chem. B 2003, 107 (21), 5074-5080.

5. Huckerby, T. N.; Tudor, A. J.; Dawber, J. G., Acid-Base Studies of Glutathione (L-y-Glutamyl-Lcysteinyl-L-glycine) by One- and Two-dimensional Nuclear Magnetic Resonance Spectroscopy. J. Chem. Soc., Perkin Trans. 2 1985, 0, 759-763.

6. Drobot, B.; Steudtner, R.; Raff, J.; Geipel, G.; Brendler, V.; Tsushima, S., Combining luminescence spectroscopy, parallel factor analysis and quantum chemistry to reveal metal speciation - a case study of uranyl(VI) hydrolysis. Chem. Sci. 2015, 6 (2), 964-972.

7. Qian, W.; Krimm, S., Vibrational analysis of glutathione. Biopolymers 1994, 34 (10), 1377-1394.

8. Krimm, S.; Bandekar, J., Vibrational Spectroscopy and Conformation of Peptides, Polypeptides, and Proteins. In Adv. Protein Chem., Anfinsen, C. B.; Edsall, J. T.; Richards, F. M., Eds. Academic Press: 1986; Vol. 38, pp 181-364.

9. Kretzschmar, J.; Haubitz, T.; Hübner, R.; Weiss, S.; Husar, R.; Brendler, V.; Stumpf, T., Network-like arrangement of mixed-valence uranium oxide nanoparticles after glutathioneinduced reduction of uranium(VI). Chem. Commun. 2018, 54 (63), 8697-8700.

10. Kretzschmar, J.; Brendler, E.; Wagler, J.; Schmidt, A.-C., Kinetics and activation parameters of the reaction of organoarsenic(V) compounds with glutathione. J. Hazard. Mater. 2014, 280, 734740 . 